\title{
ENGAGING THE APPLICATIONS COMMUNITY OF THE FUTURE SURFACE WATER AND OCEAN TOPOGRAPHY (SWOT) MISSION
}

\author{
M. Srinivasan ${ }^{\text {a }}$, A. Andral ${ }^{\text {b }}$, M. Dejus ${ }^{\text {b }}$, F. Hossain ${ }^{\text {c }}$, C. Peterson ${ }^{\text {d }}$, E. Beighley ${ }^{\text {e }}$, T. Pavelsky ${ }^{\text {f }}$, Y. Chao ${ }^{\text {g }}$, B. Doorn ${ }^{\text {h }}$, E. Bronner \\ , L. Houpert ${ }^{\mathrm{b}}$
}

a Jet Propulsion Laboratory, California Institute of Technology, Pasadena, CA, USA - margaret.srinivasan@jpl.nasa.gov

${ }^{\mathrm{b}}$ CNES, Toulouse, France - (alice.andral, michel.dejus, emilie.bronner, laurence.houpert)@cnes.fr

${ }^{\mathrm{c}}$ University of Washington, Seattle, WA, USA - fhossain@uw.edu

${ }^{\mathrm{d}}$ MSU Science and Technology Center, Stennis Space Center, LA, USA - craigp@gri.msstate.edu

${ }^{\mathrm{e}}$ Northeastern University, Boston, MA, USA - r.beighley@neu.edu

${ }^{\mathrm{f}}$ University of North Carolina, Chapel Hill, NC, USA - pavelsky@unc.edu

${ }^{\mathrm{g}}$ Remote Sensing Solutions, Pasadena, CA, USA - ychao001@gmail.com

${ }^{\mathrm{h}}$ NASA, Washington D.C., USA - bradley.doorn@nasa.gov

\section{Commission VI, WG VI/4}

KEY WORDS: Applications, Hydrology, Oceanography, Operational, SWOT

\begin{abstract}
:
NASA and the French space agency, CNES, with contributions from the Canadian Space Agency (CSA) and United Kingdom Space Agency (UKSA) are developing new wide swath altimetry technology that will cover most of the world's ocean and surface freshwater bodies. The proposed Surface Water and Ocean Topography (SWOT) mission will have the capability to make observations of surface water (lakes, rivers, wetland) heights and measurements of ocean surface topography with unprecedented spatial coverage, temporal sampling, and spatial resolution compared to existing technologies. These data will be useful for monitoring the hydrologic cycle, flooding, and characterizing human impacts on a changing environment.
\end{abstract}

The applied science community is a key element in the success of the SWOT mission, demonstrating the high value of the science and data products in addressing societal issues and needs. The SWOT applications framework includes a working group made up of applications specialists, SWOT science team members, academics and SWOT Project members to promote applications research and engage a broad community of potential SWOT data users. A defined plan and a guide describing a program to engage early adopters in using proxies for SWOT data, including sophisticated ocean and hydrology simulators, an airborne analogue for SWOT (AirSWOT), and existing satellite datasets, are cornerstones for the program. A user survey is in development and the first user workshop was held in 2015, with annual workshops planned.

The anticipated science and engineering advances that SWOT will provide can be transformed into valuable services to decision makers and civic organizations focused on addressing global disaster risk reduction initiatives and potential science-based mitigation activities for water resources challenges of the future. With the surface water measurements anticipated from SWOT, a broad range of applications can inform inland and coastal managers and marine operators of terrestrial and oceanic phenomena relevant to their work.

\section{INTRODUCTION}

Space-based altimetry is a mature remote sensing technique and benefits from more than 20 years of continuous ocean observations. Altimetry satellites determine the distance from the satellite to the sea surface very accurately by measuring the satellite-to-surface round-trip travel time of a microwave radar pulse. There are many sources of measurement errors that are taken into account in the data processing: orbit errors, instrumental noise and errors, environmental errors (wet and dry troposphere and ionosphere), geophysical errors (e.g. atmospheric attenuation, tides, inverse barometer effects). Altimetry performance has improved dramatically due to reduction of these errors sources. Global and long-term monitoring of ocean circulation up to mesoscale processes is now possible. Hundreds of applications in scientific and operational areas can be realized. Indeed, with continued altimetry observations, it is possible to observe phenomena occurring over longer time periods; the rise in global mean sea

\footnotetext{
${ }^{*}$ Corresponding author.
}

level and climatic events such as El Niño, La Niña and the Pacific Decadal Oscillation. Moreover, as data are made available within a few hours, the measurements can be used in ocean, meteorological and climate forecast models.

Typical nadir altimetry satellite orbits giving priority to temporal coverage such as Topex/Poseidon and the Jason series satellites (10-day revisit capability, inclination $66^{\circ}$, altitude $1,300 \mathrm{~km}$ ), or giving priority to spatial coverage such as ERS, Envisat or SARAL (35-day revisit capability, inclination $98^{\circ}$, altitude $800 \mathrm{~km}$ ) allow along-track measurements in all weather conditions, at a rate of $1 \mathrm{~Hz}$ or higher. These orbits are complementary and the satellites are used in operations to provide users with multi-mission products with combined higher spatial and temporal resolutions.

Conventional nadir altimetry measurements lose stability and precision as the satellite ground track approaches coasts or complex surface hydrological regions (e.g., river systems). Moreover spatial and temporal coverage are currently limited in observing smaller scale (under $200 \mathrm{~km}$ ) phenomena. With 
Cryosat-2, the future Sentinel-3 (2015), and Jason-CS (2020) missions, synthetic aperture radar (SAR) altimetry will provide new challenges and new performance capabilities.

NASA, CNES, the Canadian Space Agency and the UK Space Agency are collaborating on a new space mission to build and operate the Surface Water and Ocean Topography (SWOT) satellite, based on a new technical concept: wide-swath interferometric altimetry. The partnership is based on 25 years of CNES/NASA cooperation in the field of oceanographic altimetry with Topex/Poseidon and the Jason satellite series (Jason-1, Jason-2 and the 2015-planned launch of Jason-3). SWOT is the first satellite to join both land hydrology and oceanography communities into a single satellite mission. With a launch date scheduled for late 2020, SWOT will allow mapping surface water extent and elevation of rivers wider than $100 \mathrm{~m}$, lakes larger than $\sim 0.06 \mathrm{~km}^{2}$, and will resolve ocean and near coastal eddies to scales around $10 \mathrm{~km}$. SWOT will be considered as a revolution in hydrology science by providing the first global survey of Earth's surface water.

In the U.S., the SWOT mission was recommended by the National Research Council Decadal Survey (NRC, 2007). The French space agency, CNES, has included the SWOT mission in its program for Earth Observation Future, and the French government has allocated funds from the French Investment Program for development of SWOT.

A successfully implemented SWOT satellite will provide a science mission with significant applications potential. It will provide data products to facilitate the use of the satellite observations by a wide variety of users (operational, commercial, civic, governmental). It will also open up a new avenue for scientific research and at the same time create a new operational sector, particularly in hydrology where space observations are developing. NASA and CNES share the goal of involving Early Adopters of products in the process of SWOT data development in order to leverage hydrology and oceanography applications.

We are currently experiencing the Anthropocene age of surface water where it is redistributed and artificially managed to the extent that there is no pristine river basin left today in populated regions. These impacts are largely the result of water diversions, dams and irrigation projects that massively redistribute surface water due to the growing needs of global food, energy and water supplies. Approximately $10 \%$ of the world's energy and $20 \%$ of food are produced by artificially managed surface water. This will likely play a more dominant role in the $21^{\text {st }}$ century with many large dams planned in developing nations. For example, United States Geological Survey (USGS) records indicate an increase in irrigation acreage from 35 million acres (1950) to 65 million acres (2005) in the U.S. alone (Kenny, et al., 2009). The latter is equivalent to a withdrawal of $177 \mathrm{~km}^{3}$ of annual surface and ground water. Similarly, there were about 75,000 reservoirs built in the U.S. alone during the last century with a total capacity close to one year's mean runoff (Graf, 1999).

It has become more intractable to understand the management of predicting water downstream. Water is frequently transferred between basins or heavily regulated through reservoir sysytems. Physical models are limited in predicting surface water availability for routine applications. Without in-situ observations, wide swath elevation data from a space-based platform such as SWOT will provide will advance our understanding of changing global water availability.

\section{THE SWOT MISSION}

\subsection{A Swath Altimeter in Ka Band}

The key instrument payload is a Ka-band radar interferometer (KaRIN) capable of making high-resolution wide swath altimetry measurements with antennae at opposite ends of a 10 $\mathrm{m}$ boom. Because the elevation error increases with the look angle, KaRIN has a near nadir look angle from $1^{\circ}$ to $4^{\circ}$ leading to a swath of $50 \mathrm{~km}$ each side of the nadir (Figure 1). SWOT will provide a nearly global coverage of the earth between \pm $77.6^{\circ}$ latitude due to its inclination and its repeat period of 21 days.

However, radar interferometer measurement is sensitive to the stability of the spacecraft and is prone to large-scale errors. To address this issue, the SWOT payload includes a conventional profile altimeter for calibration and validation of the interferometer measurement for its large-scale performance. This will also allow filling the $\pm 10 \mathrm{~km}$ gap at the nadir track. Thus this approach would enable the demonstration of the transition of profile altimeter to swath altimeter for observing ocean surface topography over a wide range of scales. If successful, SWOT will then establish swath altimetry as the standard for future measurement of ocean surface topography (Fu, 2013).

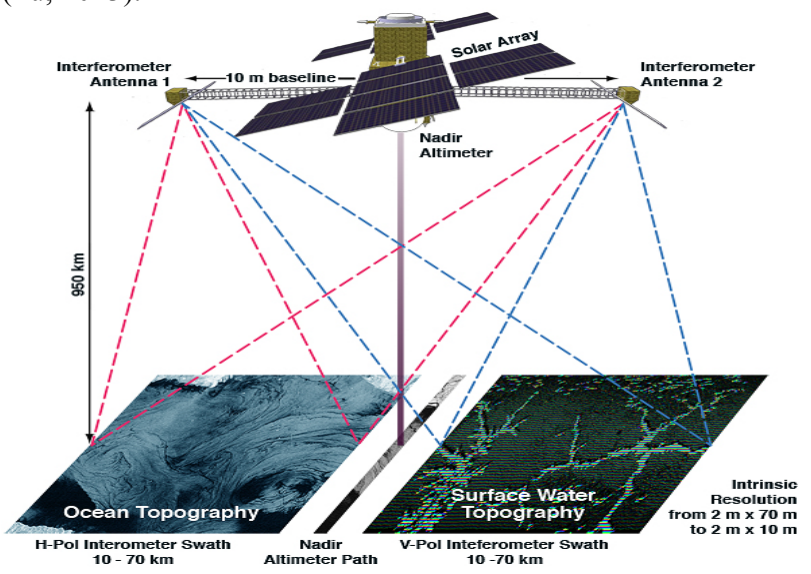

Figure 1. A schematic illustration of the SWOT measurement configuration. Credit: NASA/JPL.

SWOT promises high-precision measurement over both land surface water and the ocean. The sampling capability of SWOT will enable the measurement of ocean surface topography at scales not resolvable by current altimeters. Over the deep oceans, the SWOT planned resolution is $1 \times 1 \mathrm{~km}$ with an error at $2.4 \mathrm{~cm} / \mathrm{km}^{2}$. Over land, SWOT will work in a high-resolution mode turned on by a mask. It will resolve $100 \mathrm{~m}$ wide rivers (baseline, with a goal of $50 \mathrm{~m}$ ) and lakes (of areas greater than $250 \mathrm{~m}^{2}$ ), wetlands, and reservoirs. The water level elevations will have an accuracy of $10 \mathrm{~cm}$ and a slope accuracy of 1.7 $\mathrm{cm} / 1 \mathrm{~km}$ over $1 \mathrm{~km}^{2}$, for example, a $10 \mathrm{~km}$ reach of a $100 \mathrm{~m}$ wide river.

\subsection{Scientific Objectives in Hydrology}

River discharge and lake water storage are critical elements of land surface hydrology but are poorly observed globally. Freely available stream gauge networks cover only a few river basins. The flux of water through rivers is known to approximately $+/$ $20 \%$ at large scales but not at scales small enough to reflect the dominant processes governing the water cycle. Water storage can only be measured in the largest lakes and reservoirs, but most variability in water storage is in smaller water bodies. 
Nadir altimeters can see $60 \%$ of lakes with an area greater than $100 \mathrm{~km}^{2}$ but this only represents 15 percent of global storage change (Figure 2). Millions of small lakes and rivers have yet to be mapped and monitored for seasonal and annual changes.

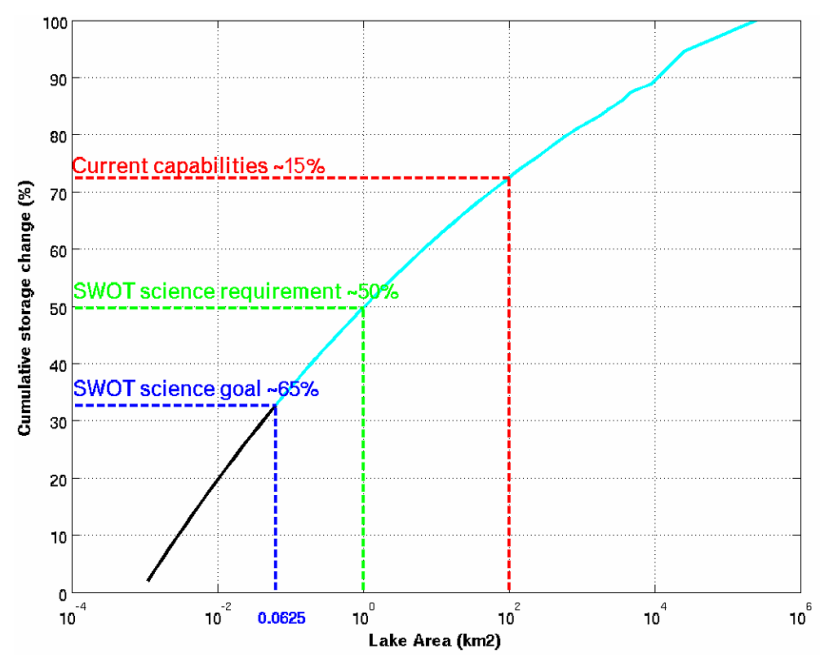

Figure 2. Cumulative global lake storage change (in \%) (Biancamaria et al., 2010).

The SWOT satellite mission will provide high-resolution measurements of water surface elevations with global coverage. It will inventory a majority of medium to large lakes (approximately 250 meters square and larger) and estimates $65 \%$ of the global lake storage change (Biancamaria, 2010).

SWOT will be the first satellite to provide a global assessment of water resources, including transboundary rivers, lake and reservoir storage and river dynamics. These unprecedented measurements will support scientific research for a better understanding of the global water cycle on land, to study the dynamics of floodplains and wetlands, which have important impacts on flood control and the balance of ecosystems.

\subsection{Scientific Objectives in Oceanography}

The ocean is Earth's largest reservoir of heat and carbon dioxide. Ocean currents are the mechanism responsible for redistributing this heat and carbon dioxide, and for bringing the climate system into balance to make our planet habitable. Many of these ocean currents are formed over scales too small to be measured globally by current Earth-observing satellites.

Existing technology makes satellites an efficient tool for measuring large-scale changes in the ocean such as El Niño, La Niña, and sea level variations. However, current satellites lack the necessary resolution for detecting small-scale ocean currents that contain most of the energy from circulation that powers the mixing and transport of water. These factors are important in determining how fast climate is changing.

The primary attribute of SWOT data will be the ability to produce high-resolution, nearly instantaneous "snapshots" of sea surface height $(\mathrm{SSH})$, the primary variable, along with information about winds and waves with similar resolution in two $50 \mathrm{~km}$-wide swaths. However, the challenge lies in the combination of this high spatial resolution with lower temporal resolution. With the 21-day exact repeat orbit needed to cover nearly the entire Earth, it will not be possible to observe the temporal development of the small-scale features that will be seen in instantaneous SSH fields. Through composite analysis and numerical models, SWOT will enable oceanographers to describe some of the mesoscale and more importantly submesoscale processes that cannot be resolved by conventional altimeter satellites. With the high spatial resolution, SWOT will also enable detailed mapping of the coastal ocean, estuaries and rivers.

For ocean studies, SWOT will provide a revolution in global, 2D observations of sea surface height with an order of magnitude less noise than traditional nadir altimetry. SWOT will measure SSH with sufficient resolution to calculate the speed and direction of ocean currents and eddies at scales of 15 $\mathrm{km}$, filling the gap between 15 and $200 \mathrm{~km}$ for ocean climate studies. Ocean currents and eddies at these short scales play a key role in the transport of heat, carbon and nutrients in the ocean and are also important to coastal processes and societal impacts of the ocean on coastal regions, such as navigation, erosion and dispersing pollutants. With modeling, scientists will have access to vertical velocities, thus improving our knowledge of heat, carbon and nutrient exchange between the surface mixed layer and deeper layers. Figure 3 illustrates the anticipated improvement in resolution from traditional altimetry compared to the expected resolution of SWOT data. For more information and a video source for this graphic visit; podaac.jpl.nasa.gov/node/431.

\subsubsection{Coastal and Estuaries Processes}

Coastal and estuarine areas are subject to strong socio-economic issues. More than $50 \%$ of the world population lives in coastal areas within $100 \mathrm{~km}$ of the shoreline. Coastal cities have an urbanization rate generally much higher than average. Those areas are very sensitive to the erosion (coast retreat) and inundation (from storm surges, floods): in Europe, approximately $75 \%$ of the shoreline is in retreat.

Most coastal zones and estuaries do not have sufficient gauging stations to understand the variability of water levels and the models are calibrated/validated with very few gauging stations, or none at all. SWOT will provide spatial information in $2 \mathrm{D}$ on the water levels in these sensitive zones under different hydrodynamic conditions. SWOT will provide access to water elevation data over coastal areas with a resolution of from 1 to 3 $\mathrm{km}$ from the coast and high-resolution data up to the coast (compared to 10 to $20 \mathrm{~km}$ with current nadir altimetry).

Over the coast, SWOT will provide observations to study the combined effects of tides, waves, storm surges and sea level rise on the spatial and temporal variation of water levels. This will allow better modeling of these phenomena and the variability of water levels, and will help understand their impacts on inundations and coastal morphological evolution (erosion/sedimentation and shoreline retreat).

In estuaries, SWOT will support studies to better understand the interaction between different bodies of water (river, tributaries, groundwater and sea), in order to:

- Better model the variation of water levels in all parts of the estuary and particularly in key sectors such as mouth or island areas, and

- Analyze the impacts on flooding and estuary morphosedimentary evolution. 


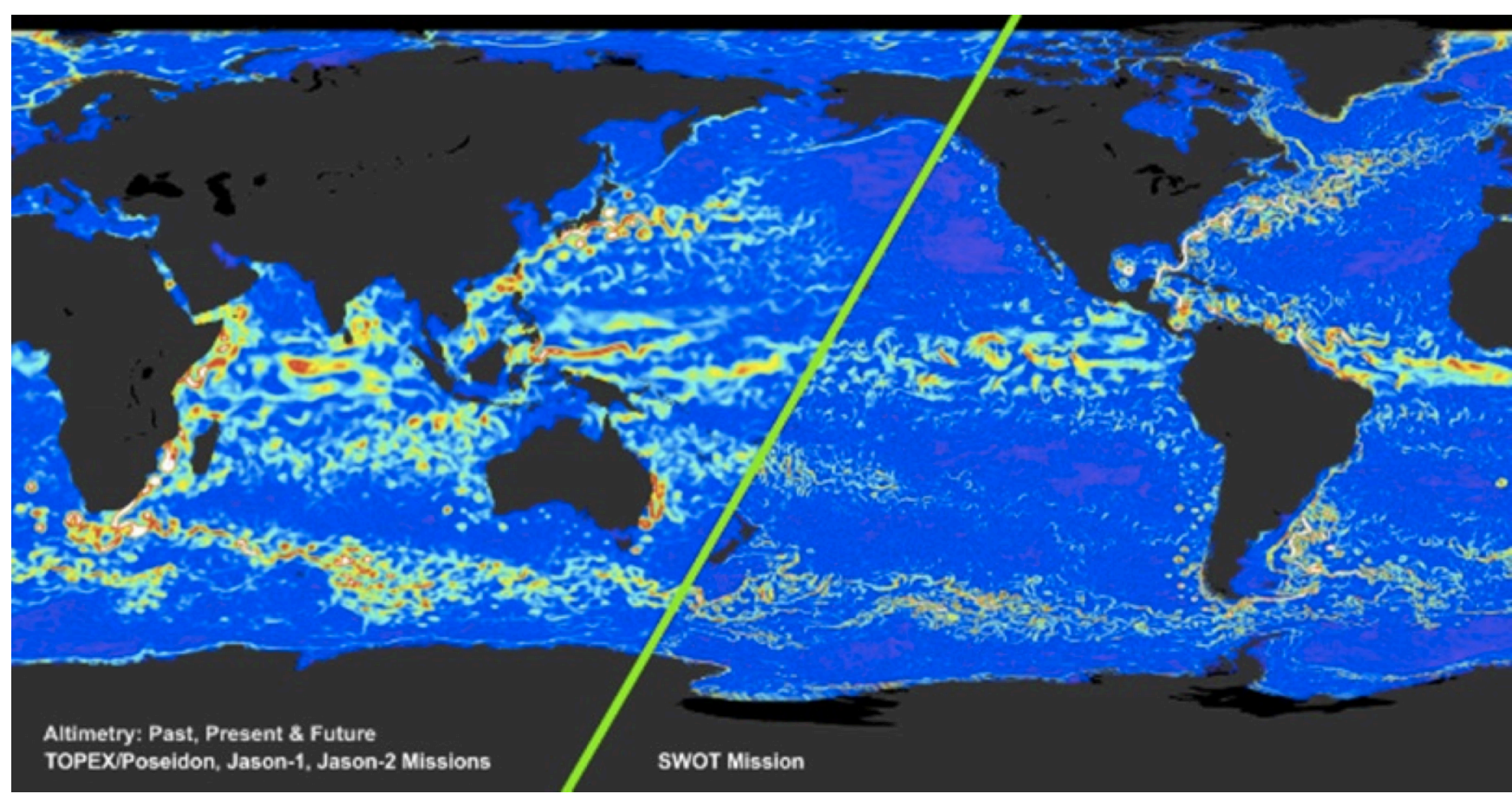

Figure 3. Comparison of data resolution from simulated past and current altimetry missions on the left side of the graphic and expected SWOT data resolution on the right. Credit: NASA/JPL.

\subsection{Data Products}

Successful strategies to enhance science and support the practical use of projected SWOT data streams will require discourse and cooperation between the science, societal applications, and mission planning communities. At approximately five years before launch, the expected data products for ocean and surface water listed in the paragraphs below are in the current development plan. Specific criteria for resolution, latency, spatial coverage, etc., are still in development.

Aside from spacecraft payload data products, the expected products relevant to applications will include the following ocean data in a swath-oriented, geographically-fixed grid:

1. Sea surface heights,

2. Wind speed (but not direction),

3. Estimated sea surface slope, and

4. Nadir altimeter products consistent with the Jasonseries geophysical data records (GDRs).

The Project will maintain a "goal" to generate the following ocean data products in support of operational applications (note that these are not institutionally required). Significantly for applied uses of the data, the current planning includes a goal for near real-time products that will have lower resolution and accuracy characteristics:

1. Estimates of ocean significant wave height, wind speed,

2. Level 2 ocean data products for swath and nadir altimetry, but with degraded accuracy, produced in near real-time (approximately 1 to 3-day lag from data downlink).

Surface water data products will be produced for water bodies with an area greater than $250 \mathrm{~m}^{2}$ (goal of $100 \mathrm{~m}^{2}$ ) and rivers of width greater than $100 \mathrm{~m}$ (goal of $50 \mathrm{~m}$ ). The required (R) and goal $(\mathrm{G})$ planned products include:

1. Estimated surface water elevations (R),
2. Estimated surface water elevation uncertainties (R),

3. Additional data and meta-data (e.g., collection time, water brightness) that may be required for deriving additional data products $(\mathrm{R})$,

4. Global water masks (R),

5. Global estimate of river discharge (rivers wider than $50 \mathrm{~m})(\mathrm{R})$, and

6. Topographic map of floodplain elevations (digital elevation models, or DEMs) based on many SWOT orbits $(\mathrm{G})$.

All standard data products will be delivered to NASA and CNES to be placed in a permanent archive at the end of the mission. For more specific information about expected data products visit swot.jpl.nasa.gov/files/swot/SRD_021215.pdf.

\section{SWOT APPLICATIONS APPROACH}

The primary goals of the SWOT applications program are to 1) promote the use of the future SWOT data products for the benefit of society and 2) to educate the community of potential SWOT end-users and decision makers so that they understand the mission capabilities for their specific application. By the time of the expected SWOT launch, we endeavor to increase the number of users who are interested in and able to use the measurements that come from the mission.

In order to constrain the scope and focus efforts we suggest the following pillars/foci for applications activities;

- Hydrology: developing world water problems, food security (flooding \& drought),

- Oceanography: coastal applications (circulation, impacts), marine operations support/open ocean issues,

- Climate: regional capabilities, coastal and agricultural impacts.

\subsection{SWOT Applications Working Group}

The SWOT Applications Working Group (SAWG) is comprised 
of key applications-focused Project and science team members, as well as interested operational users and others with interests in applied remote sensing data for hydrology and oceanography applications. The SAWG coordinates SWOT applications activities and participates in applications-focused discussions, workshops and sessions at appropriate meetings. The working group has developed a SWOT Applications Plan, conducts applications workshops and tutorials, and will coordinate engagement of SWOT applications early adopters with the development of a SWOT Early Adopters Program Guide.

Other tasks of the SAWG include;

- Facilitating feedback between SWOT user communities and the SWOT project,

- Providing information on collaborations with different types of users and communities including those of ocean research, ice and drought studies, agricultural impacts, operational oceanography, and others,

- Designing communication strategies to target and support requirements of the user community.

\subsection{Documents and Activities}

\subsubsection{SWOT Applications Plan}

The SWOT Applications Leads, in collaboration with members of the SAWG, have developed a written plan that outlines an approach for optimizing the mission assets and outcomes (data, science research) for the benefit of society. The Joint NASA/CNES SWOT Applications Plan outlines a coordinated and collaborative NASA and CNES applications program for the mission. This program, funded by NASA's Earth Science Division, Applied Science Program (ASP), and by the French Investment Program (FIP), is intended to identify, promote and support applied uses of future SWOT and AirSWOT data products by a diverse user community. The plan can be accessed from the SWOT Applications web page at swot.jpl.nasa.gov/applications.

\subsubsection{Early Adopters}

A formalized program to engage potential end-users has been developed and is expected to begin implementation in 2015 . This 'Early Adopter' program is modeled after the successful Soil Moisture Active Passive (SMAP) Early Adopter program (smap.jpl.nasa.gov/science/early-adopters/), and will similarly target potential SWOT user communities to support applied applications research. The SAWG will solicit applications for work that would benefit from the use of SWOT data sets. A significant goal of this program is to facilitate pre-launch feedback on future SWOT data products, and to accelerate the use and integration of those products into applications postlaunch by providing specific support to Early Adopters who commit to engage in pre-launch applied research.

This is a non-funded (by the SWOT Project) activity for projects to be completed with quantitative metrics prior to launch. Applications for inclusion in this program will be solicited in a call for submittals later this year on the SWOT Applications web page.

\subsubsection{User Survey}

A user survey intended to assess user needs, capabilities, and concerns is in development and will be posted on the SWOT Applications web page in the near term. The outcomes of the survey are anticipated to include a greater understanding of user interests in the level of data products (temporal frequency, latency, format, etc.), access abilities, and areas of interest.

\subsubsection{Workshops, Tutorials, Conferences}

The SAWG will continue to host user workshops to target potential data users for applications in hydrography and oceanography. In workshops convened with water resources managers and others responsible for and interested in assessing freshwater transport and disposition, mission scientists can support the review and assessment of how SWOT and AirSWOT science results may improve on information, products and collaborations for use in decision-making. Collaborations between science team members and Early Adopters will also focus on the development of tools that may be used to inform decision makers on:

- River, lake and reservoir levels,

- Flood assessments and potential mitigation measures and water storage,

- Climatic and ecological impacts on water resources,

- Water demands for agriculture and agricultural impacts from changes in water resources,

- Sustainable use of water, and

- Many other application areas and societal benefits.

\section{INTERNATIONAL COMPONENTS AND COOPERATION}

\subsection{Applications Imperatives}

One of the more noticeable impacts of SWOT for applications may be realized in the vast regions of the developing world that are mostly ungauged and yet rapidly experiencing the role played by humans in altering surface water distribution (dams, levees, reservoirs, channelization, irrigation, etc). In particular, SWOT will provide a unique contribution to transboundary water resources issues related to flooding, drought, hydropower, inland navigation and seasonal scale water management. Surface water that crosses international boundaries poses unusual challenges for its modeling, prediction and management. There are around 260 transboundary lakes and river basins that cover more than $40 \%$ of the Earth's land surface and account for an estimated 60 percent of global freshwater flow (Hossain et al., 2013). Among these, the Nile, Niger, Mekong, Indus, Irrawaddy, GBM (Ganges, Brahmaputra and Meghna), Salween and Zambesi are examples that host some of the world's largest population centers. The differences in ground network coverage, monitoring protocols to data recording and sharing, and lack of resources raise the challenge for coordinated surface water modeling in rivers in these basins.

One application that currently suffers most from a lack of basinwide coordination of river modeling is flood forecasting in downstream flood-prone regions. Forecasting of transboundary flooding in nations downstream of these basins remains notoriously difficult using conventional modeling approaches that rely on extensive in-situ data. It is expected that SWOT's ability to provide spatially distributed information of surface water bodies (rivers and lakes) will significantly enhance modeling systems for flood forecasting, data assimilation, drought management and even hydropower generation.

Given the clear impacts of SWOT's potential value for applications in the developing world, international cooperation and regional modeling and assessment of the value of currently available altimetry data in transboundary basins is key. Several investigations are under way which indicate how best to 
integrate SWOT measurements to further enhance applications. For example, Yoon and Beighley (2014) have explored how SWOT measurements could aid in flood routing of a system of reservoirs in the developing world where there is virtually no ground data. Hossain et al. (2014a, 2014b) have explored the use of nadir altimetry for extending the range of operational flood forecasting for the Bangladesh Government. More recent studies, such as Maswood and Hossain (2015) demonstrate how the dual availability of river width and height can reduce the error of river level simulations in hydrodynamic models up to $300 \%$ for downstream nations.

\subsubsection{Applied Science at NASA}

The NASA Earth Science Directorate Applied Sciences Program (ASP) funds projects that enable innovative uses of NASA Earth science data with respect to policy, business, and management decisions. ASP is supporting missions, including the SWOT concept, that were identified in the Earth Science Decadal Survey (NRC, 2007). Applications teams are tasked with implementing Decadal Survey and NASA climate-centric architecture goals related to applications.

Activities include working with international partners to identify and organize potential applications communities, and to develop and promoting a process to optimize the reach of existing applications efforts to enhance the applications value of the missions. Another goal is to promote project-level awareness of mission planning decisions that may increase or decrease the utility of data products to diverse user and potential user communities (NASA, 2011).

\subsubsection{SWOT Applications at CNES}

The French Investment Program (FIP) is the primary driver for the CNES SWOT Applications directives and approach. Innovative and economic aspects of the SWOT mission are highly relevant for the support of the mission by the FIP. Fundamental considerations for the program recognize the high climatic and environmental stakes we face as a global community in the decades to come: How can we improve our models to answer critical questions about current and future trends? What observational accuracies will be required?

For the SWOT oceanography user community, existing elements can be built upon from the framework of conventional altimetry to reach new users with applications in the highresolution data that SWOT will provide. This will lead to improvement of existing applications and new perspectives especially for coastal areas

As SWOT will be the first global survey of Earth's surface water, the hydrology community will see dramatic advancements in access to information and avenues for decision support. Still, much remains to be accomplished. The pillars of this approach will include:

- Outreach - stemming from the AVISO registered users' database gathering more than 6,000 people, as a tool for operational users to receive information about product parameters and availability. AVISO resources such as RSS feeds, newsletters, IOS/Android apps will be used to reach end-users,

- Existing operational agencies; Mercator Ocean, MyOcean,

- Support of downstream services development.

The goals of the CNES along with the FIP are to:
- Develop space applications for the water sector,

- Develop services and technologies based on available data products,

- Build on existing outreach resources, engage and inform stakeholders of SWOT capabilities,

- Define a business model that includes cost reduction for value added products (required by FIP),

- Standardize products and processing to meet user requirements.

\section{POTENTIAL APPLICATIONS OF SWOT DATA}

In addition to science focus areas, the operational applications concentrations for the SWOT mission include water management, transboundary rivers, insurance, and ocean and coastal uses, among many others.

\subsection{Water Resources Management}

Flow regulation by dams and reservoirs is commonly used for water resources management, flood risk management, hydropower generation, navigation, water supply, irrigation, and recreation. To enable and maximize these uses, reservoir storage and releases are controlled by operation rules. However, in many locations, especially in transboundary river basins, access to these operation rules or in situ measurements of reservoir inflows, outflows and storage is limited. In these cases, the behavior of reservoirs throughout a river system is very difficult to simulate to assess the potential impacts of climate, land cover, or water use changes, which are common concerns in many systems. The SWOT mission will provide the measurements to overcome the challenges associated with including reservoirs in basin-wide hydrologic models. In a recent study, Yoon and Beighley (2014) present a coupled hydrologic-reservoir modeling system based on synthetic SWOT measurements. The study showed that 1 to 3 years of measurements provided sufficient knowledge of reservoir operation to develop characteristics storage patterns. Using these patterns, they were able to simulate stream flow throughout the regulated system.

\subsection{Flood Forecasting}

So far, nadir altimetry applications for flood forecasting or river modeling have been reasonably successful and have provided good justification for the potential value of SWOT data in similar applications. A nadir altimetry (Jason-2) satellite-based flood forecasting system (Hossain et al., 2014) that has been implemented in Bangladesh, accurately detected the monsoonal flood wave swelling from the north in the upstream Indian region of the Brahmaputra basin and tributaries during the 2014 flood season. Heavy rains engorged the Brahmaputra, Jamuna, and Teesta rivers in India and Bangladesh. Rushing waters disintegrated several flood control embankments. According to the Daily Star Newspaper of Bangladesh, over 3,500 families had already been displaced and many acres of crop fields were damaged (see servirglobal.net).

In general, it has been shown that Jason-2 altimetry data affords an additional three days of lead-time in forecasting for Bangladesh with acceptable skill (Hossain et al., 2013). Current success of Jason-2 for enhancing flood forecasting indicates that the application community is poised to leverage a series of altimeters - including the ICESat-2 laser altimeter, Jason-3 (2015), Sentinel 3A/3B, Cryosat-2, and eventually, SWOT. This constellation of altimeters will provide an unprecedented global view of Earth's surface water. As human regulatory controls on 
water render the use of stand-alone hydrologic-hydraulic models less adequate, the ability of these additional "eyes in the sky", particularly a mission with the capabilities that SWOT will provide, due to the expected high resolution observations, will provide more frequent, accurate and distributed observations of surface water heights and will become increasingly important.

In another study on river modeling for enhancing water management over large ungauged basins (Maswood and Hossain, 2015), it was found that it is possible to reduce uncertainty by $300 \%$ in river level simulations by using satellites suites to overcome the lack of ground data. By using satellite precipitation data (microwave and infrared), radar altimeter data (microwave), and visible data together, one is able to 'see' many of the river flow controlling factors that a single sensor simply could not have allowed. For example, by joint use of radar altimetry and Landsat data inferred the cross section of rivers, a practical feat not yet reported in literature for river modeling.

Most water management agencies in need of physical modeling or a river basin are usually accustomed to thinking in an environment either where there is 'data' on the ground, or where the lack of such data means they can do no modeling. SWOT may change this notion by providing coincident height and width of surface water bodies and promote synergistic suite datasets from various sensors, along with SWOT data.

\subsection{Insurance and Commerce}

Given the challenges associated with assessing flood hazards and risks for regions with limited in situ measurements, the SWOT mission will provide the insurance industry with a unique opportunity. Although, SWOT is not intended to sample instantaneous flooding conditions, the measurements provided from repeat overpasses will enable users to estimate local hydraulic controls. Relative to existing elevations from the Shuttle Radar Topography Mission (SRTM), the SWOT mission will provide both a range in water surface elevations (i.e., repeat visits), as well as improved accuracy. SWOT-based river elevations will be used to estimate reference river elevations for improved localized hazard estimates. Although the SWOT mission is intended to advance our understanding of river hydrodynamics, the resulting data products represent a significant increase in complexity relative to SRTM. The SWOT early adopter program will enable potential users to fully understand expected SWOT measurements, accuracies, uncertainties and data formats and develop applications to utilize the data prior to mission launch. Thus, users will be able to benefit from SWOT as soon as data products become available

The commercial sector is driven by the need to define and address profitable markets for data products that can be provided by remote sensing systems. An assessment of market opportunities for altimetry products for use by commercial organizations will need to focus on areas that offer a demand for data products that is large enough to support a profitable business. Data product development and analysis capabilities need to provide information products that are not readily available by other technologies. AirSWOT and SWOT may be able to fill significant gaps.

\subsection{Estuaries and Coastal Regions}

SWOT will also support strategies to protect coastal floodplains, as well as the development of harbors and navigation channels in estuaries. Monitoring water levels and morphological changes associated with these activities is essential for navigation, economic development, and security of property and people from inundations and coastal retreat.

SWOT will provide observations that will support;

- Identification, survey \& mapping of seasonal and interannual variability of water level and inundations (flooding, storm surge),

- Understanding the interactions between different water bodies and their impact on the water level and changes in the estuary zonation related to the sea level rise,

- Survey and mapping of the seasonal and interannual changes of water areas in wetlands (areas with high ecological value),

- Survey and mapping of the islands and channels changes, and

- Ecological conservation and restoration: evolution of fauna and flora and their habitats in relation to the water level.

SWOT will also greatly improve observations of coastal ocean features. Altimetry near the coast is currently limited by the relatively large measurement footprint that makes it difficult to observe features within $10 \mathrm{~km}$ of coasts. SWOT's planned 1 $\mathrm{km}$ resolution oceanographic products would fill in this gap (Callahan, et al., 2012).

\subsection{Marine Operations and Fisheries}

Marine operators such as marine transporters, commercial fishing vessels, oil companies with offshore production facilities, and recreational boaters, to name a few, will be able to use data from SWOT. The high-resolution information about ocean circulation and the finer scale resolution (10 to $200 \mathrm{~km}$ over the ocean) could be highly beneficial to optimizing their operations in both coastal and open ocean environments.

Fisheries operations may also benefit from long term, regional observations of ocean conditions that may be provided from these data by observing and measuring physical properties of the ocean that influence fish habitats and migration. Altimetry data products, particularly the higher resolution SWOT products, can be combined with other sensor data (ocean color, wind measurements, ocean temperature, salinity) to provide critical information for support of good fisheries management practices, optimizing operations, safety at sea and more.

\subsection{Climate and Weather}

Better understanding of the finer scale movement of energy in the ocean, and of the vertical transport of carbon and heat is crucial for understanding the role of the ocean in regulating climate change. Accurate knowledge of large-scale circulation is also required. Higher SWOT measurement accuracy from submesoscale (less than $200 \mathrm{~km}$ ) to global scale will support critical climate studies as we navigate into a future of a warmer world.

\section{CONCLUSIONS}

The SWOT mission will provide measurements unique to hydrology; repeated global observations of rivers on scales of 
$100 \mathrm{~m}$ wide, lakes and reservoirs on scales of $250 \mathrm{~m}^{2}$ in size, and sea surface topography to 1 kilometer. These measurements will have the potential to revolutionize the understanding of surface hydrological processes and the applied uses and societal benefits of remote sensing observations.

SWOT will provide a major improvement for oceanography and hydrology scientific research, as well as operational and practical applications, with primary foci including;

- Oceanography: First global determination of the ocean circulation, kinetic energy and dissipation at high resolution, mesoscale and submesoscale ocean circulation features, including those impacting marine operations.

- Hydrology: First global inventory of fresh water storage and its change on a global basis, including river flow and discharge and transboundary river data.

Visit the NASA Applied Sciences website at appliedsciences.nasa.gov for information about applications of NASA's satellite missions. Additional information about the mission and about SWOT applications initiatives can be found at the NASA SWOT Applications web page (swot.jpl.nasa.gov/applications/), and at the CNES applications web page (www.aviso.altimetry.fr/en/missions/futuremissions/swot/objectives-and-applications.html).

\section{ACKNOWLEDGEMENTS}

The authors would like to acknowledge funding and support from NASA's Applied Sciences Program, the SWOT Project, and the French Investment Program.

\section{REFERENCES}

Biancamaria, S., Andreadis, K.M., Durand, M., Clark, E.A., Rodriguez, E., Mognard, N.M., Alsdorf, D. E., Lettenmaier, D.P., and Oudin, Y., 2010. Preliminary characterization of SWOT hydrology error budget and global capabilities. IEEE JSTARS, vol. 3, issue 1, doi:10.1109/JSTARS.2009.2034614.

Callahan, P., Rodriguez, E., and Fjørtoft, R., The Surface Water/Ocean Topography Mission Science Processing and Data Products, Poster, 20 Years of Radar Altimetry, Venice, https://earth.esa.int/web/guest/-/20-years-of-progress-in-radaraltimetry-symposium-7706 (24 Sep 2012).

Fu, L., Ubelman, C., 2013. On the transition from profile altimeter to swath altimeter for observing globan ocean surface topography. Journal of Atmospheric and Oceanic Technology, Volume 31, pp 560-568.

Graf, W.L., 1999. Dam nation: A geographic census of American dams and their large-scale hydrologic impacts. Water Resources Research, vol. 35(4), pp. 1305-1311.

Hossain, F., Siddique-E-Akbor, A.H.M., Biancamaria, S., Lee, H., and Shum, C.K., 2013. Proof of Concept of Altimeter-based Forecasting System for Transboundary Flooding, IEEE Journal of Selected Topics in Applied Earth Observation and Remote Sensing, 7(2): 587-601 (doi:10.1109/JSTARS.2013.2283402).

Hossain, F., Maswood, M., Siddique-E-Akbor, A.H.M., Yigzaw, W., Mazumder, L.C., Ahmed, T., Hossain, M., ShahNewaz, S., Limaye, A., Lee, H., Pradhan, S., Shrestha, B., Bajracharya, B., Shum, C.K., Turk, F.J., 2014a. A Promising Radar Altimetry Satellite System for Operational Flood
Forecasting in Flood-prone Bangladesh IEEE Magazine on Geosciences and Remote Sensing (doi:0.1109/MGRS.2014.2345414).

Hossain, F., Shum, C.K., Turk, F.J., Biancamaria, S., Lee, H., Limaye, A., Hossain, M., Shah-Newaz, S., Mazumder, L.C., Ahmed, T., Yigzaw, W., and Siddique-E-Akbor, A.H.M., 2014b. A Guide for Crossing the Valley of Death: Lessons Learned from Making a Satellite based Flood Forecasting System Operational and Independently Owned by a Stakeholder Agency, Bulletin of American Meteorological Society (BAMS), August 2014 (doi:10.1175/BAMS-D-13-00176.1).

Kenny, J.F., Barber, N.L., Hutson, S.S., Linsey, K.S., Lovelace, J.K., Maupin, M., 2009. Estimated Use of Water in the United States in 2005, USGS Circular: 1344 (ISBN: 978-1-4113-26002).

Maswood, M. and Hossain, F. 2014. Advancing River Modeling in Ungauged River Basins using Remote Sensing: The Case of Ganges-Brahmaputra-Meghna Basins. Journal of River Basin Management, accepted.

Moons, T., 1997. Report on the Joint ISPRS Commission III/IV Workshop "3D Reconstruction and Modelling of Topographic Objects," Stuttgart, Germany, http://www.radig.informatik.tumuenchen.de/ISPRS/WG-III4-IV2-Report.html (28 Sep. 1999).

NASA Earth Science Applied Sciences Program Annual Report, 2011.

NASA-CNES SWOT Applications Plan, 2014, http://swot.jpl.nasa.gov/files/swot/Final_SWOT\%20Application s\%20Plan_D79129.pdf

NRC, 2007, http://www.nap.edu/catalog/11820/earth-scienceand-applications-from-space-national-imperatives-for-the

Smith, J., 1987a. Close range photogrammetry for analyzing distressed trees. Photogrammetria, 42(1), pp. 47-56.

Smith, J., 1987b. Economic printing of color orthophotos. Report KRL-01234, Kennedy Research Laboratories, Arlington, VA, USA.

Smith, J., 1989. Space Data from Earth Sciences. Elsevier, Amsterdam, pp. 321-332.

Smith, J., 2000. Remote sensing to predict volcano outbursts. In: The International Archives of the Photogrammetry, Remote Sensing and Spatial Information Sciences, Kyoto, Japan, Vol. XXVII, Part B1, pp. 456-469.

Yoon Y. and Beighley, R.E., 2014. Simulating streamflow on regulated rivers using characteristic reservoir storage patterns derived from remotely sensed water surface elevations, Hydrological Processes, DOI:10.1002/hyp.10342.

Copyright: Some of the work reported here was performed at the Jet Propulsion Laboratory, California Institute of Technology, under contract with the National Aeronautics and Space Administration. Copyright 2015. All rights reserved. 